\title{
METODE BIOKONTROL IKAN CUPANG (Betta splendens) SEBAGAI PENGENDALI VEKTOR PENYAKIT DBD DI KARTASURA KABUPATEN SUKOHARJO
}

\author{
Sri Harsono ${ }^{1}$, Arifatun Nisaa ${ }^{2 *}$ \\ ${ }^{1}$ Prodi Biologi, FKIP, Universitas Veteran Bangun Nusantara \\ ${ }^{2}$ Prodi Perekam \& Informasi Kesehatan, FKM, Universitas Veteran Bangun Nusantara \\ *Email: sriharsono18@gmail.com ${ }^{1}$, arifatun.nisaa@gmail.com ${ }^{2}$
}

\begin{abstract}
ABSTRAK
Latar belakang: Pemanfaatan ikan sebagai predator alami larva nyamuk adalah salah satu cara pengendalian secara biologi yang mudah untuk dilakukan oleh masyarakat. Metode pengendalaian secara biologis ini dapat mengurangi kepadatan larva nyamuk serta tidak menimbulkan masalah bagi kesehatan lingkungan Pengendalian DBD secara non kimiawi ini bisa dilakukan dengan memanfaatkan ikan cupang.

Metode Penelitian: Design penelitian ini adalah penelitian kuantitatif menggunakan study cross sectional. Teknik pengumpulan data menggunakan data sekunder dari dinas kesehatan dan survey pendahuluan, kemudian data primer berupa Hasil isian kuesioner responden berupa pre test dan post test. Teknik sampling menggunakan teknik quota sampling sedangkan metode analisis data menggunakan uji Paired T Test.

Hasil \& Pembahasan: Ada perbedaan tingkat pengetahuan responden sebelum dan sesudah edukasi. Sedangkan dalam pelaksanaan simulasi pencegahan DBD dengan ikan Cupang pada 33 responden, terdapat 29 responden yang berkurang bahkan tidak ada jentik nyamuk setelah diberi Ikan Cupang didalam rumah sedangkan 4 responden lainnya memang dari awal implementasi, tidak ditemukan jentik nyamuk didalam rumah.

Kesimpulan: Dalam rangka pencegahan penyakit DBD selain 3M+ yang diantaranya menebar bubuk abate dan ikan cupang, warga juga diimbau untuk menanam tumbuhan seperti bunga lavender dan daun sereh karena mampu mengusir nyamuk dari aroma yang dikeluarkan.

Kata kunci: pengetahuan, demam berdarah dengue, pengendalian DBD, biokontrol DBD
\end{abstract}

Background: The use of fish as a natural predator of mosquito larvae is one method of biological control that is easy to do by the community. This biological control method can reduce the density of mosquito larvae and does not cause problems for environmental health. Nonchemical DHF control can be done by using betta fish.

Research Methods: The design of this study is quantitative research using cross sectional study. Data collection techniques using secondary data from the health department and preliminary surveys, then primary data in the form of the results of the questionnaire respondents in the form of pre-test and post-test. The sampling technique uses quota sampling technique while the data analysis method uses the Paired T Test.

Results \& Discussion: There are differences in the level of knowledge of respondents before and after education. While in the implementation of the DHF prevention simulation with Betta fish in 33 respondents, there were 29 respondents who were reduced even without mosquito larvae after being given Betta Fish in the house while 4 other respondents were indeed from the beginning of implementation, no mosquito larvae were found in the house.

Conclusion: In the context of preventing DHF in addition to $3 \mathrm{M}+$ which includes spreading abate powder and betta fish, residents are also encouraged to plant plants such as lavender flowers and lemongrass leaves because they are able to repel mosquitoes from the aroma issued.

Keywords: knowledge, dengue hemorrhagic fever, DHF control, DHF biocontrol 


\section{PENDAHULUAN}

Dalam rangka mengurangi dampak negatif dari kondisi lingkungan, maka diperlukan pengendalian vektor nyamuk penyebab DBD. Peraturan Menteri Kesehatan RI Nomor 374 tahun 2010 tentang Pengendalian Vektor, menyatakan bahwa ada beberapa metode yang dapat digunakan diantaranya adalah metode pengendalian fisik dan mekanis yang merupakan upaya-upaya untuk mencegah, mengurangi, menghilangkan habitat perkembangbiakan dan populasi vektor secara fisik dan mekanik. Selain metode pengendalian fisik dan mekanis, terdapat juga metode pengendalian dengan menggunakan agen biotik dan metode pengendalian secara kimia.

Pengendalian penularan penyakit DBD di Indonesia terutama dilakukan dengan menggunakan insektisida golongan organofosfat (malation dan temefos) untuk menurunkan kepadatan vektornya. Malation dan temefos selalu digunakan dalam program nasional pengendalian DBD di Indonesia sejak tahun 1970-an. Penggunaan larvasida dalam waktu yang lama dapat menimbulkan resistensi. Pengendalian secara biologis merupakan upaya pemanfaatan agen biologi untuk pengendalian vektor DBD. Beberapa agen biologis yang sudah digunakan dan terbukti mampu mengendalikan populasi larva vektor DB/DBD adalah dari kelompok bakteri, predator seperti ikan pemakan jentik dan cyclop (Copepoda). Predator larva di alam cukup banyak, namun yang bisa digunakan untuk pengendalian larva vektor DBD tidak banyak jenisnya dan yang paling mudah didapat dan dikembangkan masyarakat serta murah adalah ikan pemakan jentik (Depkes, 2011).

Menurut Yogyana, L. (2013) upaya pengendalian demam berdarah secara biologi salah satunya dengan memelihara ikan. Pemanfaatan ikan dalam upaya pengendalian demam berdarah efektif dilakukan pada stadium larva, terutama larva instar III karena pada stadium ini larva mudah diidentifikasi dengan ciri adanya rambut pada seluruh tubuh, kepala tampak menghitam, tingkat metabolisme yang belum matur serta pergerakan yang lebih banyak.

Pemanfaatan ikan sebagai predator alami larva nyamuk adalah salah satu cara pengendalian secara biologi yang mudah untuk dilakukan oleh masyarakat. Metode pengendalaian secara biologis ini dapat mengurangi kepadatan larva nyamuk serta tidak menimbulkan masalah bagi kesehatan lingkungan (Depkes, 2010). Berdasarkan beberapa hasil penelitian yang telah dilakukan, ikan menunjukkan kemampuan yang berbeda dalam mengendalikan larva nyamuk. Penelitian Taviv dkk (2011) menunjukkan bahwa ikan cupang (Betta $s p$.) yang efektif untuk pengendalian larva Aedes aegypti adalah ikan dengan ukuran $4 \mathrm{~cm}$ atau $5 \mathrm{~cm}$. Ikan cupang tidak mati walaupun di kontainer terdapat atau ditaburi abate. Selanjutnya terbukti bahwa pemanfaatan ikan cupang (Betta $s p$.) plus pemantau jentik lebih efektif meningkatkan Angka Bebas Jentik (ABJ) dan menurunkan House Index (HI), Container Index (CI), Breteau Index (BI) dibandingkan hanya dengan pemantau jentik.

Perkasa (2010) menyatakan bahwa ikan cupang (Betta sp.) merupakan ikan yang cukup dikenal dan mudah diperoleh masyarakat karena selama ini ikan tersebut digunakan sebagai ikan hias dan ikan untuk permainan (diadu). Selain itu jenis ikan predator adalah ikan guppy (Poecilia reticulata). Penelitian Samsudrajat (2008) membuktikan bahwa pengendalian secara biologi dapat menggunakan ikan pemakan jentik (ikan adu atau ikan cupang), bakteri (Bt.H-14) dan ikan Poesilia reticulata (ikan guppy) dengan memakan larva. Ikan Poesilia reticulata (ikan guppy) dengan ukuran kira-kira $2 \mathrm{~cm}$ dalam waktu 1 hari dapat memangsa larva atau jentik nyamuk 
mencapai 116 ekor. Pada kontainer dengan diameter $30 \mathrm{~cm}$, ikan tersebut dapat memakan larva Aedes aegypti sebanyak 25 ekor per hari.

Berdasarkan hasil survey awal, Kartasura merupakan Wilayah yang endemik DBD. Sedangkan di Wilayah Ngadirejo, Kemasan, Kartasura, Kab. Sukoharjo masyarakat belum pernah mencoba melakukan pencegahan perkembangbiakan larva Aedes aegypti dengan Metode BioKontrol (menebarkan maupun memelihara ikan cupang) karena mereka belum tahu bahwa ikan tersebut bisa digunakan sebagai predator larva Aedes aegypti. Selama ini jika diketahui ada kasus DBD di wilayahnya, hanya diberikan edukasi $3 \mathrm{M}+$, dilakukan fogging dan pemberian bubuk abate.

Oleh karena itu, penelitian ini dilakukan dengan tujuan untuk menguji tingkat pengetahuan responden tentang Biokontrol Ikan Cupang (Betta Splendens) Sebagai Upaya Pengendalian Vektor Penyakit Demam Berdarah Dengue pada saat pretest $\&$ posttest serta mencoba mensimulasi pencegahan DBD dengan Ikan Cupang.

\section{METODE PENELITIAN}

Penelitian ini dilaksanakan di Wilayah Ngadirejo, Kemasan, Kartasura Kab. Sukoharjo pada bulan AgustusOktober 2019. Populasi dalam penelitian ini adalah seluruh warga yang berdomisili di Kec. Kartasura Kab. Sukoharjo. Sampel dalam penelitian ini diambil dengan tehnik Multi Stage Sampling yaitu: Kecamatan Kartasura $\rightarrow$ Kemasan $\rightarrow$ Ngadirejo $\rightarrow$ RW $9 \rightarrow$ RT 2. Dengan demikian sampel penelitian diperoleh sejumlah 50 responden.

Jenis penelitian ini adalah penelitian kuantitatif dengan menggunakan study cross sectional. Penelitian ini akan dilaksanakan di Wilayah Ngadirejo, Kemasan, Kartasura, Kab. Sukoharjo dengan sumber data sekunder dari buku profil kesehatan Dinkes Kab. Sukoharjo dan hasil survey pendahuluan yang dilakukan oleh peneliti. Sedangkan data primer berupa hasil pengisian kuesioner responden.

Teknik pengumpulan data dalam penelitian ini dengan menggunakan kuesioner pre test dan post test, yang diisi oleh subyek penelitian sejumlah 50 responden.

Teknik Analisis Data:

a. Untuk mengetahui gambaran karakteristik dan tingkat pengetahuan responden dilakukan secara deskriptif, menggunakan tabel distribusi frekuensi.

b. Uji Normalitas Data Uji normalitas data dalam penelitian ini dilakukan dengan uji One Sample Kolmogorov Smirnov pada taraf signifikansi 5\%.

c. Membandingkan perbedaan hasil pre test dan post test setelah diberikan media leaflet, menggunakan uji statistik Paired T Test ketika data berdistribusi normal.

\section{HASIL}

Karakteristik Responden

Tabel 1. Karakteristik Responden

\begin{tabular}{lrr}
\hline Nama Variabel & Frekuensi & $\%$ \\
\hline Jenis Kelamin: & & \\
Pria & 12 & 24 \\
Wanita & 38 & 76 \\
\hline Umur: & & \\
$21-30$ tahun & 3 & 6 \\
$31-40$ tahun & 7 & 14 \\
$41-50$ tahun & 10 & 20 \\
$51-60$ tahun & 15 & 30 \\
61-70 tahun & 15 & 30 \\
>70 tahun & 0 & 0 \\
\hline Tingkat Pendidikan: & & \\
Tidak Sekolah & 0 & 0 \\
SD & 5 & 10 \\
SMP & 1 & 2 \\
SMA & 31 & 62 \\
Perguruan Tinggi & 13 & 26 \\
\hline Status Pekerjaan: & & \\
PNS & 3 & 6 \\
Buruh & 10 & 20 \\
Karyawan Swasta & 5 & 10 \\
Wiraswasta & 8 & 16 \\
IRT/Tidak Bekerja & 24 & 48 \\
\hline
\end{tabular}


Tingkat Pengetahuan Responden tentang Metode Biokontrol Ikan Cupang (Betta Splendens) Sebagai Pengendali Vektor Penyakit Demam Berdarah Dengue di Wilayah Ngadirejo, Kemasan, Kartasura, Kab. Sukoharjo

Tingkat pengetahuan responden sebelum dan sesudah edukasi tentang dapat diketahui dengan melakukan Uji Paired Sample T Test.

Tabel 2. Paired Samples Statistics

\begin{tabular}{|c|c|c|c|c|}
\hline & Mean & $\mathrm{N}$ & $\begin{array}{c}\text { Std. } \\
\text { Deviation }\end{array}$ & $\begin{array}{l}\text { Std. } \\
\text { Error } \\
\text { Mean }\end{array}$ \\
\hline $\begin{array}{ll}\text { Pair } & \\
1 & \\
1 & \text { Post } \\
& \text { Test }\end{array}$ & $\begin{array}{l}76.20 \\
84.10\end{array}$ & $\begin{array}{l}50 \\
50\end{array}$ & $\begin{array}{l}6.966 \\
6.444\end{array}$ & $\begin{array}{l}.985 \\
.911\end{array}$ \\
\hline
\end{tabular}

Tabel 3. Paired Samples Correlations

\begin{tabular}{|l|c|c|c|}
\hline & $\mathrm{N}$ & Correlation & Sig. \\
\hline $\begin{array}{l}\text { Pair Pre Test \& } \\
1 \quad \text { Post Test }\end{array}$ & 50 & .911 & .000 \\
\hline
\end{tabular}

Hasil uji menunjukkan bahwa korelasi antara dua variabel adalah sebesar 0.911 dengan sig sebesar 0.000 . Hal ini menunjukkan bahwa korelasi antara dua rata-rata tingkat pengetahuan sebelum dan sesudah edukasi adalah kuat dan signifikan.

Nilai t hitung adalah sebesar 19.442 degan sig 0.000. Karena sig < 0.05 maka dapat disimpulkan bahwa Ho ditolak, artinya ada perbedaan tingkat pengetahuan responden sebelum dan sesudah edukasi, dengan demikian dapat dinyatakan bahwa edukasi yang diberikan mempengaruhi peningkatan pengetahuan responden.

Implementasi Metode Biokontrol Menggunakan Ikan Cupang Sebagai Predator Larva Aedes Aegypti

Beberapa metode pengendalian vektor telah banyak diketahui dan digunakan oleh program pengendalian DBD di tingkat pusat dan di daerah yaitu: Manajemen lingkungan, Pengendalian
Biologis, Pengendalian Kimiawi, Partisipasi masyarakat, Perlindungan Individu dan Peraturan perundangan. Dalam penelitian ini termasuk pengendalian Biologis. Pengendalian secara Biologis merupakan upaya pemanfaatan agent biologi untuk pengendalian vektor DBD. Beberapa agen biologis yang sudah digunakan dan terbukti mampu mengendalikan populasi larva vektor DB/DBD adalah dari kelompok bakteri, predator seperti ikan pemakan jentik dan cyclop (Copepoda) (Pusat Data \& Surveilans Epidemiologi, 2010).

Tabel 5. Gambaran Implementasi Metode Biokontrol Menggunakan Ikan Cupang Sebagai Predator Larva Aedes Aegypti

\begin{tabular}{lllll}
\hline & \multicolumn{3}{c}{$\begin{array}{l}\text { Sesudah } \\
\text { Perlakuan }\end{array}$} \\
\hline \multirow{3}{*}{$\begin{array}{l}\text { Sebelum } \\
\text { Perlakuan }\end{array}$} & \multicolumn{3}{c}{ Ada } & Tidak \\
\cline { 2 - 5 } & Ada & 0 & 29 & 29 \\
\cline { 2 - 5 } & Tidak & 0 & 4 & 4 \\
\cline { 2 - 5 } & Total & 0 & 33 & 33 \\
\hline
\end{tabular}

Dari 50 responden ada 33 rumah yang menjadi subyek penelitian, kemudian diberi Ikan Cupang di dalam rumahnya, ditempatkan ditempat yang berpotensi ada jentik nyamuk. Hasil penelitian menunjukkan bahwa rumah yang ada jentik nyamuknya menjadi benar-benar tidak ada jentik ketika diletakkan ikan cupang ditempat tersebut (biasanya ada jentik ditempat tersebut). Meskipun ini hanya bersifat menggambarkan. Namun, hal ini menunjukkan bahwa memang benar Ikan Cupang mampu dijadikan sebagai predator dari jentik nyamuk.

\section{PEMBAHASAN}

Metode Biokontrol Menggunakan Ikan Cupang Sebagai Predator Larva Aedes Aegypti

Pemanfaatan ikan sebagai predator alami larva nyamuk adalah salah satu cara pengendalian secara biologi yang 
mudah untuk dilakukan oleh masyarakat. Metode pengendalaian secara biologis ini dapat mengurangi kepadatan larva nyamuk serta tidak menimbulkan masalah bagi kesehatan lingkungan (Depkes, 2010). Konsentrasi pestisida dalam fogging ini hanya bersifat sementara karena hanya dapat membunuh nyamuk-nyamuk dewasa, tidak dengan jentik-jentik nyamuknya (Nurmaulina dan Sumekar, 2016). Bahkan dalam melakukan fogging ini juga dapat membunuh predator lainnya yang dapat menggangu rantai makanan. Sehingga nyamuk-nyamuk masih akan dapat hidup dan berkembang biak (Mutmainah, Prasetyo dan Sugiarti, 2017).

Berdasarkan beberapa hasil penelitian yang telah dilakukan, ikan menunjukkan kemampuan yang berbeda dalam mengendalikan larva nyamuk. Penelitian Taviv dkk (2011) menunjukkan bahwa ikan cupang (Betta $s p$.) yang efektif untuk pengendalian larva Aedes aegypti adalah ikan dengan ukuran $4 \mathrm{~cm}$ atau $5 \mathrm{~cm}$. Ikan cupang tidak mati walaupun di kontainer terdapat atau ditaburi abate. Selanjutnya terbukti bahwa pemanfaatan ikan cupang (Betta $s p$.) plus pemantau jentik lebih efektif meningkatkan Angka Bebas Jentik (ABJ) dan menurunkan House Index (HI), Container Index (CI), Breteau Index (BI) dibandingkan hanya dengan pemantau jentik.

Ikan Cupang Pemakan Jentik Nyamuk DBD Disebar di Kota Tasikmalaya sebagai bentuk Upaya pencegahan penyakit DBD lewat habitat air bersih (Mutmainah, Prasetyo dan Sugiarti, 2017). Upaya penanggulangan penyebaran penyakit DBD itu langsung menggandeng komunitas ikan Cupang di Kota Cimahi (Saktiansyah, 2014). Ikan Cupang tak akan berbau saat dipelihara di air bersih seperti bak mandi atau penampung air yang rentan sebagai media jentik nyamuk mematikan tersebut. Dinas Pertanian dan Perikanan
Kota Tasikmalaya ini mengikuti kebijakan strategi sejumlah kota lain yang sudah menerapkan metode penyebaran ikan cupang dalam membasmi jentik nyamuk.

Predator larva di alam cukup banyak, namun yang bisa digunakan untuk pengendalian larva vektor DBD tidak banyak jenisnya, dan yang paling mudah didapat dan dikembangkan masyarakat serta murah adalah ikan pemakan jentik. Di Indonesia ada beberapa ikan yang berkembang biak secara alami dan bisa digunakan adalah ikan kepala timah dan ikan cetul. Namun ikan pemakan jentik yang terbukti efektif dan telah digunakan di kota Palembang untuk pengendalian larva DBD adalah ikan cupang. Meskipun terbukti efektif untuk pengendalian larva Ae.aegypti, namun sampai sekarang belum digunakan oleh masyarakat secara luas dan berkesinambungan. Dari pengamatan penulis, pemanfaatan ikan pemakan jentik harus difasilitasi oleh Pemerintah daerah dan pembinaan dari sektor terkait, karena masyarakat Indonesia belum mampu mandiri sehingga masih harus mendapatkan dukungan penyuluhan agar mampu melindungi dirinya dan keluarga dari penularan DBD. Jenis predator lainnya yang dalam penelitian terbukti mampu mengendalikan larva DBD adalah dari kelompok Copepoda atau cyclops, jenis ini sebenarnya jenis Crustacea dengan ukuran mikro. Namun jenis ini mampu makan larva vektor DBD. Beberapa spesies sudah diuji coba dan efektif, antara lain Mesocyclops aspericornis diuji coba di Vietnam, Tahiti dan juga di Balai Besar Penelitian Vektor dan Reservoir, Salatiga. Peran Copepoda dalam pengendalian larva DD/DBD masih harus diuji coba lebih rinci di tingkat operasional.

Kasus demam berdarah dengue makin merebak. Musim hujan jadi pemicu maraknya kasus ini. Hal ini menyebabkan orang makin dituntut untuk waspada sekaligus melakukan 
pencegahan mandiri termasuk menjaga kebersihan lingkungan rumah agar bebas dari jentik nyamuk. Ada cara alami yang digaungkan Kementerian Kesehatan yakni dengan memelihara ikan cupang. Rupanya ikan yang lebih sering dipelihara sebagai ikan hias dan ikan aduan ini dianggap mampu membantu manusia memerangi DBD. Ikan cupang relatif memiliki harga murah dan cukup efektif memakan jentik nyamuk penyebab DBD (Yulian Taviv, 2010). Keampuhan ikan cupang dalam memerangi DBD ternyata bukan sekadar isapan jempol belaka. Sebuah riset menemukan ikan cupang lebih efektif menjadi predator alami jentik nyamuk daripada ikan guppy. Penelitian yang diterbitkan di Jurnal Sains Nasional Universitas Nusa Bangsa ini membandingkan daya predator antara ikan cupang dan ikan guppy. Hasilnya, ikan cupang memiliki daya makan paling banyak mencapai 89 ekor jentik dalam waktu enam jam. Sedangkan ikan guppy paling banyak hanya 47 ekor dalam waktu 6 jam (Mutmainah, Prasetyo dan Sugiarti, 2017). Ikan cupang akan efektif ditempatkan pada bak-bak atau wadah penampungan air yang tidak bisa ditutup seperti penampung air hujan. Ada beberapa titik di rumah yang bisa dijadikan sarang nyamuk seperti, bak kamar mandi dan toilet, tempat penampungan air, air jebakan semut (kaki meja), air pembuangan kulkas, tempat minum burung yang jarang diganti, pot bunga, dispenser air minum (wadah limpahan airnya), barang bekas di sekitar rumah (ban, kaleng, batok kelapa, botol, gelas air mineral, potongan bambu, dan semua tempat yg bisa nenampung air). Satu jentik akan menjadi nyamuk dewasa dalam waktu 12-14 hari. Nyamuk betina dewasa sekali bertelur dapat menghasilkan 100-150 telur. Dalam kurun waktu sebulan nyamuk bisa bertelur sebanyak empat kali sehingga telru bisa sekitar 400-600 per bulan.

\section{PENUTUP}

Kesimpulan

Dalam rangka pencegahan penyakit DBD selain $3 \mathrm{M}+$ yang diantaranya menebar bubuk abate dan ikan cupang, warga juga diimbau untuk menanam tumbuhan seperti bunga lavender dan daun sereh karena mampu mengusir nyamuk dari aroma yang dikeluarkan.

\section{Saran}

a. Jangan salah sasaran dalam melakukan Pemberantasan Sarang Nyamuk (PSN) bukan memotong pohon, bersih-bersih rumput, menata bunga, dan lain-lain, karena jentik tidak bersarang di rerumputan.

b. Untuk penelitian selanjutnya bisa dilakukan dengan metode kuasi eksperimen yang menunjukkan perbedaan jumlah jentik nyamuk sebelum dan sesudah perlakuan.

\section{DAFTAR PUSTAKA}

Barera R., M. A. dan G. G. C. (2006) "Ecological Factors Influencing Aedes aegypti (Diptera: Culicidae) Productivity in Artificial Containers in Salinas, Puerto Rico," Med. Entomology, 43(3), hal. 484-492.

Bouzid, M. et al. (2014) "Climate change and the emergence of vector-borne diseases in Europe: case study of dengue fever.," BMC public health, 14, hal. 781. doi: 10.1186/1471-2458-14-781.

Brunkard, J. M. et al. (2007) "Dengue Fever Seroprevalence and Risk Factors , Texas - Mexico," Emerging Infectious Diseases, 13(10), hal. 1477-1483.

Cahyati, W. H. (2006) "Dinamika Aedes Aegypti sebagai Vektor Penyakit Kesehatan Masyarakat," 2, hal. 40-50.

Felipe J, Colon Gonzalez, Carlo Fezzi, R Lake, P. R. H. (2013) “The Effects of Weather and Climate Change on Dengue," PLoS Neglected Tropical Diseases, 7(11), hal. 1-9. doi: 
10.1371/journal.pntd.0002503.

Mutmainah, S., Prasetyo, E. dan Sugiarti, L. (2017) "DAYA PREDASI IKAN CUPANG (Betta splendens) DAN IKAN GUPPY (Poecilia reticulate) TERHADAP LARVA INSTAR III NYAMUK Aedes aegypti SEBAGAI UPAYA PENGENDALIAN VEKTOR PENYAKIT DEMAM BERDARAH DENGUE (DBD)," Jurnal Sains Natural, 4(2), hal. 98-106.

Nisaa, A. (2015) Analisis Spasial Dinamika Lingkungan Terkait Kejadian DBD Berbasis SIG di Kecamatan Colomadu, Kabupaten Karanganyar. Universitas Gadjah Mada.

Nurmaulina, W. dan Sumekar, D. W. (2016) "Upaya Pengendalian Vektor Demam Berdarah Dengue, Aedes aegypti L . MenggunakanBioinsektisida The Effort to Control Vektor of Dengue Haemoraghic fever , Aedes aegypti L . by Using Bioinsectiside," Majority, 5(April), hal. 131-135.

Pusat Data \& Surveilans Epidemiologi, K. R. (2010) "Masalah Vektor DBD \& Pengendaliannya di Indonesia," Buletin Jendela Epidemiologi, 2.

Saktiansyah, L. A. (2014) Analisis Spasial dan Faktor-Faktor Yang Berhubungan Dengan Kejadian
Demam Berdarah Dengue (DBD) di Kelurahan Wates Kecamatan Wates Kabupaten Kulon Progo Tahun 2013. Universitas Gadjah Mada.

Tavares, A.O., Mario Monteiro., M.A. Vargas., R. S. (2014) "Land Use Change and Forest Routing in a Rural Context: The Relevance of The Community-Based Management and Planning Framework," Applied Geography, 52, hal. 153-171. doi: 10.1016/j.apgeog.2014.05.008.

Wen, T.-H. et al. (2010) "Spatialtemporal patterns of dengue in areas at risk of dengue hemorrhagic fever in Kaohsiung, Taiwan, 2002.," International journal of infectious diseases: IJID: official publication of the International Society for Infectious Diseases, 14(4), hal. e334-43. doi: 10.1016/j.ijid.2009.06.006.

Yulian Taviv, A. S. dan H. S. (2010) "Pengendalian DBD Melalui Pemanfaatan Pemantau Jentik dan Ikan Cupang di Kota Palembang," Buletin Penelitian Kesehatan, 38(4), hal. 198-207.

Yogyana, L. 2013. Hubungan karakteristik lingkungan kimia dan biologi dengan keberadaan larva aedes aegypti di wilayah endemis DBD di Kelurahan Kassi-Kassi Kecamatan Rappocini Kota Makassar tahun 2013. 